\title{
Whole body vibration training during allogeneic hematopoietic cell transplantation-the effects on patients' physical capacity
}

\author{
Antonia Pahl ${ }^{1}$ (D) $\cdot$ Anja Wehrle ${ }^{2} \cdot$ Sarah Kneis $^{1} \cdot$ Albert Gollhofer $^{3} \cdot$ Hartmut Bertz $^{1}$
}

Received: 23 May 2019 / Accepted: 14 January 2020 / Published online: 23 January 2020

(C) The Author(s) 2020

\begin{abstract}
Patients undergoing allogeneic hematopoietic cell transplantation (alloHCT) experience a considerable decline in physical and psycho-social capacity. Since whole body vibration (WBV) is known to efficiently stimulate the neuromuscular system and enhance cardiorespiratory fitness and muscle strength in frail individuals, we hypothesized that WBV would maintain various physical and psychological capacities in patients during alloHCT. Seventy-one patients were randomly allocated to either an intervention group (IG) doing WBV or an active control group (CG) doing mobilization exercises five times per week. We determined peak oxygen consumption $\left(\mathrm{VO}_{2 \text { peak }}\right)$ and maximum power, maximum strength, functional performance, body composition, quality of life (QoL), and fatigue. Tests were carried out before conditioning therapy, at hospital discharge and at day \pm 180 (follow-up). As 18 patients did not participate in post-intervention assessment and follow-up data from 9 patients was not collectible, per-protocol (PP) analysis of 44 patients is presented. During hospitalization, WBV maintained maximum strength, height, and power output during jumping, as well as reported QoL, physical functioning, and fatigue level compared with mobilization. At follow-up, relative $\mathrm{VO}_{2 \text { peak }}(p=0.035)$ and maximum power $(p=0.011)$, time and power performing chairrising test $(p=0.022 ; p=0.009)$, and reported physical functioning $(\mathrm{p}=0.035)$ significantly increased in the IG, while fatigue decreased $(p=0.005)$. CG's body cell mass and phase angle had significantly decreased at follow-up $(p=0.002 ; p=0.004)$. Thus, WBV might maintain maximum strength, functional performance, QoL, and fatigue during alloHCT, while cardiorespiratory fitness might benefit from accelerated recovery afterwards.
\end{abstract}

Keywords Stem cell transplantation $\cdot$ Resistance exercise $\cdot$ Exercise therapy $\cdot$ Leukemia $\cdot$ Side effects $\cdot$ Galileo®

\section{Background}

Allogeneic hematopoietic cell transplantation (alloHCT) is usually associated with hospitalization lasting at least 4 weeks. The treatment itself, therapy-related side effects, and bed rest

Electronic supplementary material The online version of this article (https://doi.org/10.1007/s00277-020-03921-x) contains supplementary material, which is available to authorized users.

Antonia Pahl

antonia.pahl@uniklinik-freiburg.de

1 Department of Medicine I, Medical Center-University of Freiburg, Hugstetterstr. 55, 79106 Freiburg, Germany

2 Institute for Exercise and Occupational Medicine, Medical Center-University of Freiburg, Hugstetterstr. 55,

79106 Freiburg, Germany

3 Department of Sport and Sport Science, University of Freiburg, Schwarzwaldstraße 175, 79117 Freiburg, Germany and physical inactivity lead to a general decline in physical performance, maximum oxygen consumption, muscular performance in particular, and quality of life $(\mathrm{QoL})$ as a consequence of all impairments [1-5]. Poor maximum oxygen consumption and peak exercise capacity are associated with a higher risk of cardiovascular diseases and all-cause mortality [6-9]. Furthermore, muscle mass and strength loss are inter alia associated with higher risk of falls and mortality in cancer patients [10-12]. These impairments thus restrict patients' autonomy, QoL, and ultimately, their overall survival $[13,14]$. To counteract such declines, several studies investigated the effects of exercises during therapy [15-18]. There is ample evidence that physical exercise in form of aerobic or multimodal exercise programs (including moderate resistance exercises) is feasible and can positively influence patients' functional performance even during alloHCT [19-22]. Nonetheless, it remains unclear how cardiopulmonary fitness and muscle strength can both be maintained most efficiently. Considering that muscular capacity is one predictor for 
maximum oxygen consumption [23], focusing on musclepreserving exercises might be particularly relevant for alloHCT patients. Cunningham et al. [24] showed that resistance training can counteract protein degradation initiated by bed rest and medical treatment and may therefore maintain muscle mass during alloHCT. However, engaging in conventional resistance training during alloHCT is restricted according to current recommendations. Thus, patients' blood values, i.e., platelets counts, and well-being limit the intensity and volume of resistance training $[25,26]$. Therefore, whole body vibration (WBV) presents a gentler resistance training method, as it does not additionally exacerbate cardiovascular stress while exercising [27], and reveals similar EMG activity as resistance exercises with external loads [28]. WBV is applied through a vibration platform upon which the subjects stand; it produces alternating sinusoidal movements of the lower body [29]. Thus, WBV induces involuntary, frequency-dependent, repeating eccentric, and concentric muscle contractions in the legs culminating in a tonic vibration reflex that enhances the recruitment of motor units during static or dynamic exercises $[30,31]$. Consequently, WBV, similar to low-intensity electrical muscle stimulation [32], enables high neuromuscular activity that can improve functional performance as well as cardiorespiratory fitness [33-35], may increase muscle strength [36], and is known to prevent muscle-mass loss during bed rest in healthy individuals $[4,37]$. In patients with chronic diseases like neurological, musculoskeletal, or metabolic disorders, WBV has proven to improve muscle strength, mobility, and balance [38]. In heart transplant recipients, Crevenna et al. [39] reported heart rates, blood pressures, and lactate concentrations after WBV that were similarly increased after aerobic endurance exercises. Thus, provided patients have no acute infection, restrictive orthopedic disease in the lower body, or untreated cardiovascular illness, no adverse events are likely [40]. We already proved its feasibility for hospitalized patients undergoing high-dose chemotherapy in a previous investigation [41]. Therefore, we hypothesized that WBV would maintain patients' cardiorespiratory fitness as a reliable representative of physical capacity and trigger further adaptations in the neuromuscular system, body composition, and QoL. Consequently, we implemented a stratified randomized controlled trial to assess the effects of WBV on patients undergoing alloHCT.

\section{Methods}

\section{Study design and patients}

Between June 2016 and October 2017, all consecutive eligible patients were recruited at the Department of Medicine I, University Medical Center Freiburg, Germany, at the day of hospital admission for alloHCT. Seventy-one patients were randomly allocated 1:1 to two parallel groups: an intervention group (IG) or an active control group (CG). Stratified randomization was based on patients' sex and conditioning chemotherapy protocol. Randomization in blocks of 10 was based on a computer-assisted pseudo-random number generator (Research Randomizer, Version 4.0). Allocation was implemented by sequentially numbered, sealed, opaque envelopes. After obtaining patient's consent, the researcher opened the next consecutively numbered envelope. Inclusion criteria were patients scheduled for alloHCT, over the age of 18 years, able to perform a cardiopulmonary exercise test, and written informed consent. Exclusion criteria were unstable bone metastasis, endoprosthesis of knee or hip, epilepsy, pacemaker, and severe cardiovascular diseases according to other studies $[42,43]$. Furthermore, patients' blood values had to fulfill safety criteria for the testing of maximum capacity on the respective day (platelets count $\geq 20.000 / \mu l$ and hemoglobin $\geq 8 \mathrm{~g} / \mathrm{dl}$ blood) [44, 45]. Parameters were assessed before conditioning therapy (baseline, T0), at hospital discharge (T1), and at follow-up about day \pm 180 post transplantation (T2). Table 1 summarizes patients' clinical information. The study was approved by the Ethics Committee of the University of Freiburg and conducted according to the Declaration of Helsinki (German Register of Clinical Trials No.: DRKS00009918).

\section{Intervention}

Both groups' one-on-one training sessions took place in the patient's room. Both groups' intervention protocol prescribed daily exercising on weekdays for approximately $20 \mathrm{~min}$ if justified by patients' well-being and blood values that had to fulfill safety criteria for exercising: platelets count $\geq 10.000 / \mu \mathrm{l}$ and hemoglobin $\geq 7.5 \mathrm{~g} / \mathrm{dl}$ without dizziness.

The IG performed WBV training of the legs standing on the side-alternating Galileo ${ }^{\circledR}$ Basic vibration platform (Novotec Medical GmbH, Pforzheim, Germany). CG performed mobilization of the spine and stretching of the whole body sitting or lying in bed or standing in front of it. For detailed information, see Supplementary file 1 and 2.

\section{Outcome measures}

In the following, a short description of outcome measures is presented. For detailed information, see Supplementary file 1.

\section{Primary endpoint}

Peak oxygen consumption (VO2peak) VO2peak (1/min) was measured during maximum cardiopulmonary exercise test (CPET). 
Table 1 Patients' characteristics

\begin{tabular}{|c|c|c|}
\hline & IG $n=18$ & $\mathrm{CG} n=26$ \\
\hline Age (years) ${ }^{\#}$ & $55(50-63)$ & $56(32-63)$ \\
\hline \multicolumn{3}{|l|}{$\operatorname{Sex}(N)$} \\
\hline Male:female & $11: 7$ & $19: 7$ \\
\hline BMI $\left(\mathrm{kg} / \mathrm{m}^{2}\right)^{\#}$ & $26.1(20.1-28.2)$ & $26(22.4-28.1)$ \\
\hline \multicolumn{3}{|l|}{ Diagnosis $(n)$} \\
\hline AML & 13 & 13 \\
\hline ALL & 1 & 2 \\
\hline CLL & 0 & 1 \\
\hline CMML & 1 & 0 \\
\hline MDS & 1 & 2 \\
\hline lymphoma & 1 & 3 \\
\hline MM & 0 & 1 \\
\hline Myelofibrosis & 1 & 0 \\
\hline Septic granulomatosis & 0 & 1 \\
\hline $\begin{array}{l}\text { Common variable } \\
\text { immunodeficiency }\end{array}$ & 0 & 1 \\
\hline SAA & 0 & 2 \\
\hline \multicolumn{3}{|l|}{ Remission at alloHCT $(n)$} \\
\hline SD & 0 & 1 \\
\hline PD & 6 & 7 \\
\hline $\mathrm{CR}$ & 8 & 9 \\
\hline PR & 1 & 1 \\
\hline Recurrence & 0 & 1 \\
\hline PIF & 1 & 3 \\
\hline Progression & 0 & 2 \\
\hline Untreated & 1 & 1 \\
\hline NMD & 0 & 1 \\
\hline N.a. & 1 & 0 \\
\hline HCT-CI score (score) ${ }^{\#}$ & $2(1-3)$ & $2(0-3)$ \\
\hline EBMT score (score) ${ }^{\#}$ & $5(3.5-5)$ & $5(4-5)$ \\
\hline Karnofsky performance index $(\%)^{\#}$ & $90(85-90)$ & $90(90-95)$ \\
\hline Cycles of chemotherapy $(n)^{\#}$ & $2(1-4)$ & $1(0-9)$ \\
\hline $\begin{array}{l}\text { Hospitalization during } \\
\text { alloHCT (days) }{ }^{\#}\end{array}$ & $38(35-43.5)$ & $41(37-44)$ \\
\hline
\end{tabular}

\# Median (range)

BMI: body mass index; $A M L$ : acute myeloid leukemia; $A L L$ : acute lymphocytic leukemia; $C L L$ : chronic lymphatic leukemia; $C M M L$ : chronic myelo-monocytic leukemia; $M D S$ : myodysplatic syndrom; $M M$ : multiple myeloma; $S A A$ : severe aplastic anemia; $S D$ : stable disease; $P D$ : progress disease; $C R$ : complete remission; $P R$ : partial remission; $P I F$ : persistent induction failure; $N M D$ : non-malignant disease; $H C T-C I$ : hematopoietic cell transplantation-comorbidity index; EBMT: European Group for Blood and Marrow Transplantation

\section{Secondary endpoints}

Cardiorespiratory fitness Cardiorespiratory fitness parameters were also measured during cardiopulmonary exercise test (CPET) in consideration of patients' body weight: peak oxygen consumption $(\mathrm{ml} / \mathrm{min} / \mathrm{kg})$ and maximum power output $(\mathrm{W} / \mathrm{kg})$.
Strength capacity We determined maximum voluntary strength of the knee extensors and flexors $(\mathrm{Nm})$ and muscular endurance of those muscles (\%) via isokinetic measurement (CONT-TREX MJ, CMV, Duebendorf, Switzerland).

Functional performance All functional performance measurements were taken on a force plate (Leonardo Mechanograph $®$ GRFP, Novotec Medical GmbH, Pforzheim, Germany) that determined dynamic ground reaction forces in their local and temporal progress.

Two common functional tasks were performed: the chairrising test and maximum counter-movement jump. We calculated the duration performing one repetition (s) and power output while getting up $(\mathrm{W} / \mathrm{kg})$. For the counter-movement jump, we calculated maximum power output during take-off per kilogram body weight $(\mathrm{W} / \mathrm{kg})$ and jumping height $(\mathrm{cm})$. Both tests evaluate leg muscle power.

Body composition To determine body fat (\%; $\mathrm{kg})$ and fat-free mass (\%), an air displacement plethysmography system (Bod Pod Body, Composition System, Life Measurement, INC) as well as bioelectrical impedance analysis (BIA, Nutriguard-S, Data Input, Pöcking, Germany) was used. Via bioelectrical impedance analysis, also body cell mass $(\mathrm{kg})$ and phase angle $\left({ }^{\circ}\right)$ were determined.

Quality of life and fatigue The EORTC QLQ-C30questionnaire (European Organization for Research and Treatment of Cancer Quality of Life) was used to assess QoL in general, and for transplantation-associated physical symptoms, the EORTC-QLQ-HDC29 was also applied.

To measure fatigue, we used the Multidimensional Fatigue Inventory questionnaire.

Physical activity To assess patients' physical activity before, since general cancer therapy, and after alloHCT, we modified the Freiburg questionnaire on physical activity (FFKA modified) according to the time interval of interest. For analysis, we grouped three categories when physical activity can be carried out: daily routine, leisure time, and sports.

\section{Sample size and statistics}

The primary endpoint $\mathrm{VO}_{2 \text { peak }}$ measured at hospital discharge was analyzed in a linear regression model with treatment allocation, baseline $\mathrm{VO}_{2 \text { peak }}$, gender, and age as independent variables. As the assumption of normal distribution (Shapiro-Wilktest) was not satisfied and because of a $38 \%$ dropout rate, all variables and endpoints were included in non-parametric perprotocol analysis. Differences in all variables between both groups and differences in groups' delta (T1-T0 and T2-T0) were assessed by Mann-Whitney $U$ test. Intragroup differences over time were computed by Wilcoxon signed-rank test. The 
level of significance was set to $p<0.05$. Group data are presented as median and $95 \%$ confidence interval $(95 \% \mathrm{CI})$. The point estimate and $95 \%$ confidence interval of the HodgesLehmann's median differences for paired groups were used to estimate the treatment effect. All statistical analyses were conducted using the IBM SPSS Version 22 software (SPSS Inc., Chicago, Illinois, USA).

\section{Results}

As 18 patients did not participate in post-intervention assessment and follow-up data from 9 patients was not collectible (Fig. 1), we present a per-protocol (PP) analysis of 44 patients who completed at least two of three measurement sessions. Groups did not differ according to patients' characteristics (Table 1) and training compliance (IG 58.8\%, 95\% CI 48.966.7; CG $60.8 \%, 95 \%$ CI 41.2-68; $p=0.962)$. A total of $99.1 \%$ of IG's exercise sessions were performed as prescribed or intensity-reduced, while two sessions had to be stopped prematurely - one because of knee pain and one because of discomfort. In the $\mathrm{CG}$, one session had to be stopped because of discomfort. No severe adverse events (e.g., bleeding, collapse, muscle rupture) occurred. Differences between groups were apparent at baseline in power during the countermovement jump, where CG performed better than IG. The linear regression model exhibited no $\mathrm{VO}_{2 \text { peak }}$ group difference (CG minus IG) at T1 (estimated as $-0.08 \mathrm{l} / \mathrm{min}$; 95\% CI $-0.22-0.07)$. It also revealed that higher age led to lower $\mathrm{VO}_{2 \text { peak }}$ and high $\mathrm{VO}_{2 \text { peak }}$ baseline values led to higher values at hospital discharge, whereas gender did not seem to influence $\mathrm{VO}_{2 \text { peak }}$.

\section{Cardiorespiratory fitness}

The $\mathrm{VO}_{2 \text { peak }}$ decreased significantly during both groups' hospitalization (IG $p=0.002$; CG $p=0.000$ ) and regained initial values after follow-up. Results of $\mathrm{VO}_{2 \text { peak }}$ and maximum power considering patients' body weight present differences between groups: during hospitalization both groups showed a decrease of maximum power (IG $p=0.005$; CG $p=0.000$ ) and $\mathrm{VO}_{2 \text { peak }}(\mathrm{IG} \mathrm{p}=0.002 ; \mathrm{CG} \mathrm{p}=0.000)$, whereas at follow-up, only IG's $\mathrm{VO}_{2 \text { peak }}(p=0.035)$ and maximum power $(p=0.011)$ significantly increased (Figs. 2 and 3$)$.

\section{Strength capacity}

After hospitalization, CG's maximum strength capacity of the knee extensors and flexors was significantly reduced (extension $p=0.003$; flexion $p=0.044$ ), while IG's values remained unchanged (Fig. 4). We observed no changes after follow-up. Strength endurance capacity did not change during hospitalization or at follow-up in either group.

\section{Functional performance}

CG's jump height is significantly reduced at hospital discharge ( $p=0.005)$. At follow-up, significantly different values between groups in favor of the IG are shown $(p=0.033)$ (Fig. 5). Maximum power during jumping is also only significantly reduced in the CG at T1 $(p=0.039)$. Both groups' time and power output during the chair-rising test remained unchanged after hospitalization but improved significantly in the IG at follow-up (time $p=0.022$; power $p=0.009$ ).

\section{Body composition}

Many body composition parameters decreased during hospitalization in both groups and exhibited similar changes between groups and the time of measurement, unlike the fatfree mass (\%) which remained unchanged in both groups. We noted differences in body cell mass and phase angle after follow-up between groups (Table 2): the IG presented an increase in the fat-free mass $(p=0.035)$, but the CG did not. Furthermore, only the CG's body cell mass was significantly reduced ( $p=0.002$ ), while the IG's regained the baseline level. We noted the same with the phase angle, which regained baseline level at T2, while the CG's was significantly reduced ( $p=$ 0.002).

\section{Quality of life and fatigue}

After hospitalization, CG patients reported reduced QoL $(p=0.015)$, while the IG's QoL remained unchanged. After follow-up, both groups reported significantly better QoL (IG $p=0.013$; CG $p=0.037$ ). The CG's physical functioning worsened during hospitalization $(p=$ $0.001)$. In contrast, IG reported improved physical functioning at follow-up $(p=0.035)$, as well as improved role functioning $(p=0.025)$, emotional functioning $(\mathrm{p}=$ $0.002)$, and social functioning $(p=0.014)$. Furthermore, both groups reported worsening gastrointestinal side effects (IG p =0.001; CG p = 0.001) after hospitalization. The CG also reported worse gastrointestinal side effects 6 months after transplantation than at baseline $(p=$ 0.019). Exacerbated skin problems were only reported by the CG after hospitalization $(p=0.001)$ and 6 months after transplantation $(p=0.026)$. Urine frequency differed between groups after hospitalization $(p=0.041)$.

Furthermore, the CG reported a significantly higher fatigue level at T1 $(p=0.005)$, while the IG's remained unchanged. They also reported significantly lower fatigue at T2 $(p=0.006)$, while CG's fatigue returned to baseline level, leading to a significant group difference over time at follow-up $(p=0.038)$. 


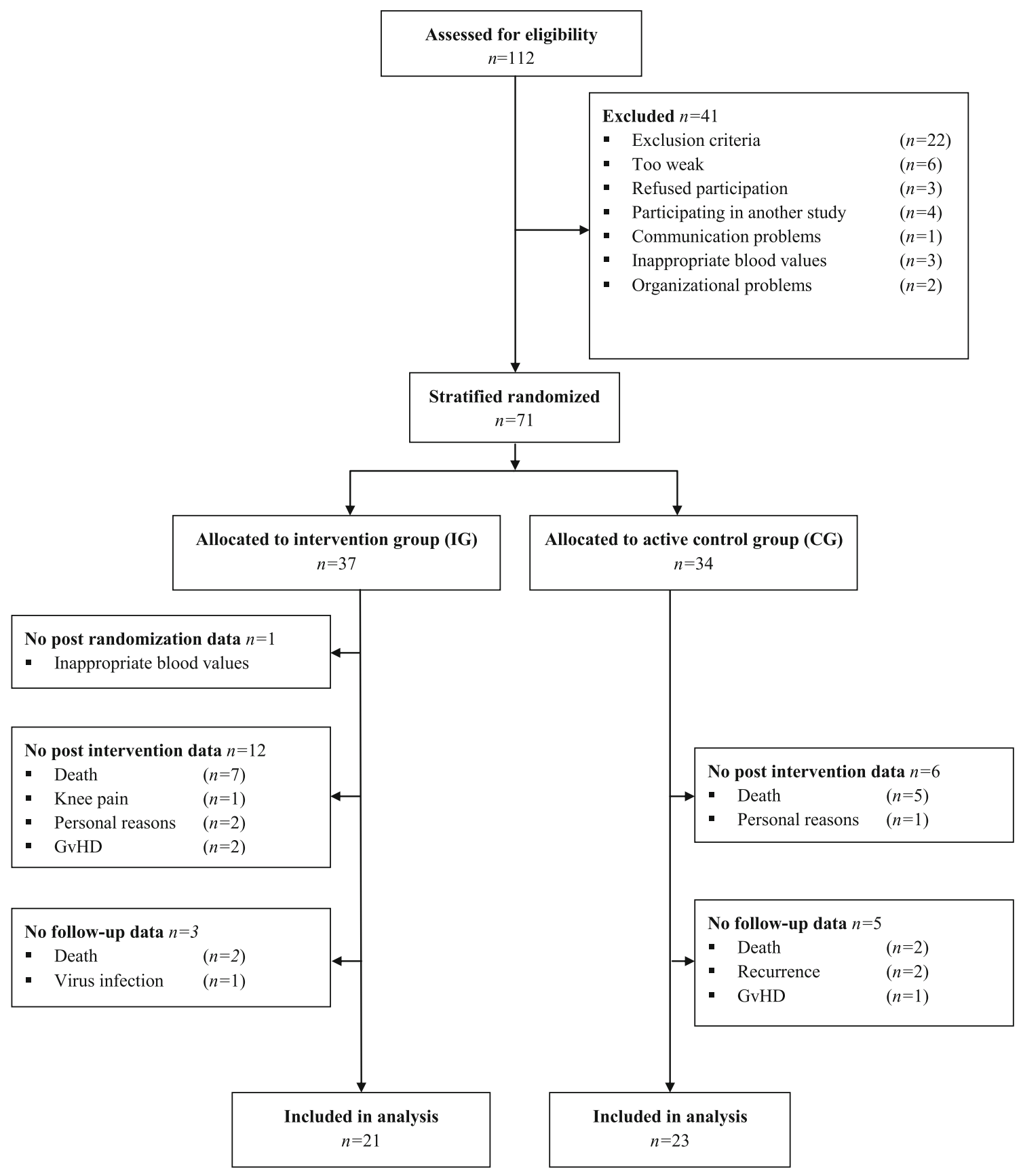

Fig. 1 Flow diagram of patient recruitment

\section{Physical activity}

The amount of physical activity carried out during sports increased with the initial cancer treatment in both groups (IG $p=0.006$; $\mathrm{CG} p=0.000)$. In contrast, IG reported significantly reduced physical activity during daily routine $(p=0.043)$ and leisure time $(p=0.023)$ after the initial cancer treatment compared with the time before. The CG reduced only their habits regarding leisure time activity $(p=0.005)$ during that time. After alloHCT, both groups reported significantly less physical activity during daily routine (IG $p=0.002$; CG $p=$
0.000) while the $C G$ also significantly reduced their physical activity during leisure time $(p=0.009)$. We observed no group differences at any time of measurement (Table 3).

\section{Discussion}

To best of our knowledge, no study so far had investigated the effects of WBV during alloHCT and we are the first to have implemented a CPET immediately upon hospital discharge. The feasibility of both can be confirmed, as we detected no 
Fig. 2 Difference of relative $\mathrm{VO}_{2 \text { peak }}$ over time. Box and whisker plots showing the lower quartile (25th percentile), median (50th percentile), upper quartile (75th percentile), and degree of dispersion as $95 \%$ confidence interval $(95 \% \mathrm{CI})$
Prism Lab

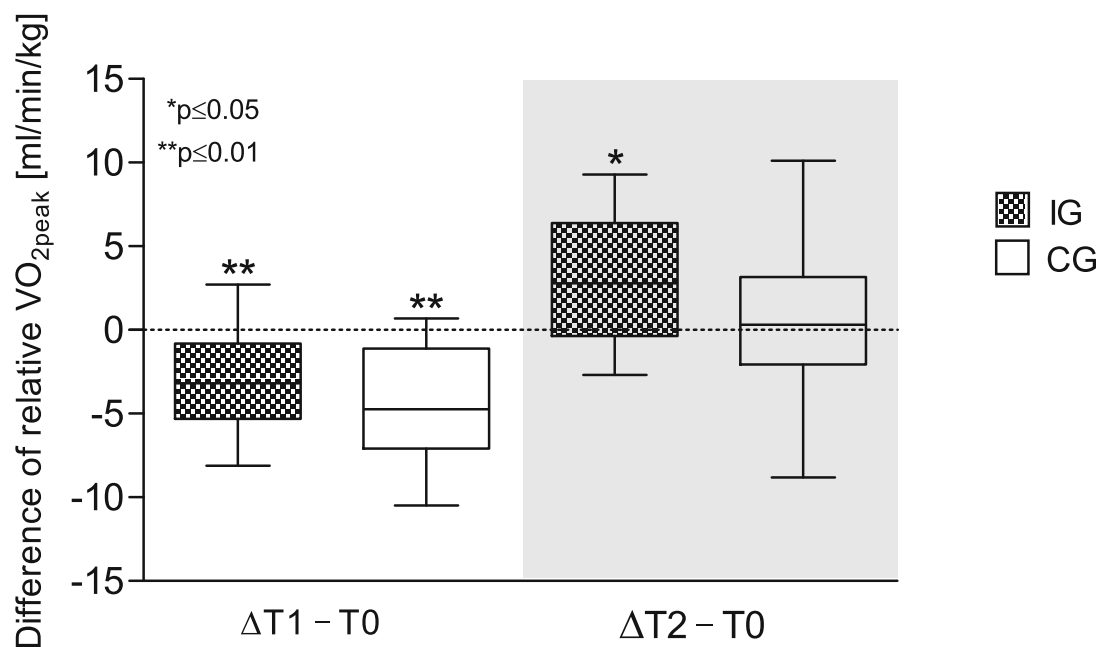

adverse events during training or testing and our dropout rate is comparable to other interventional studies $[15,19,46]$.

By implementing WBV during alloHCT, we observed a clear benefit in cardiorespiratory fitness in our IG in contrast to the CG 6 months after transplantation. We suppose that CPET performance at hospital discharge was considerably influenced by medical treatment and treatment-related side effects that impaired patients' ability to realize their maximum capacity and that obliterated the differences between groups at hospital discharge. We hypothesized that otherwise, their maximum oxygen uptake could have been maintained by $\mathrm{WBV}$, as it is rose during acute exercising [47]. Increased metabolic power due to enhanced muscular activity and a higher heart rate and lactate concentration similar to aerobic endurance exercises such as during WBV are factors supporting this hypothesis [39, 48]. Mester et al. [40] assumed that more efficient gas exchange and material metabolism between blood and muscle fibers (thanks to more opened capillaries immediately after WBV) could be one reason for increased oxygen uptake after exercise. In line with this, a WBV study in patients with pulmonary arterial hypertension revealed a $\mathrm{VO}_{2 \text { peak }}$ increase after only 4 weeks' hospitalization [33]. Their exercise prescription resembled our study. However, as our patients' diagnosis and subsequent therapy differed from the aforementioned study, we assume the medical treatment during hospitalization is the main reason for our cardiorespiratory fitness findings at hospital discharge. Nevertheless, we assume that WBV during hospitalization plays a crucial role in ensuring the IG's better cardiorespiratory fitness 6 months after transplantation. First of all, patients in both groups underwent similar physical conditioning before alloHCT-objectively measured via HCT-CI scores, the Karnofsky performance index and our baseline assessments, and subjectively, the EORTC-HDC29-questionnaire. We
Fig. 3 Difference of relative maximum power over time. Box and whisker plots showing the lower quartile (25th percentile), median (50th percentile), upper quartile (75th percentile), and degree of dispersion as $95 \%$ confidence interval $(95 \% \mathrm{CI})$
Prism Lab

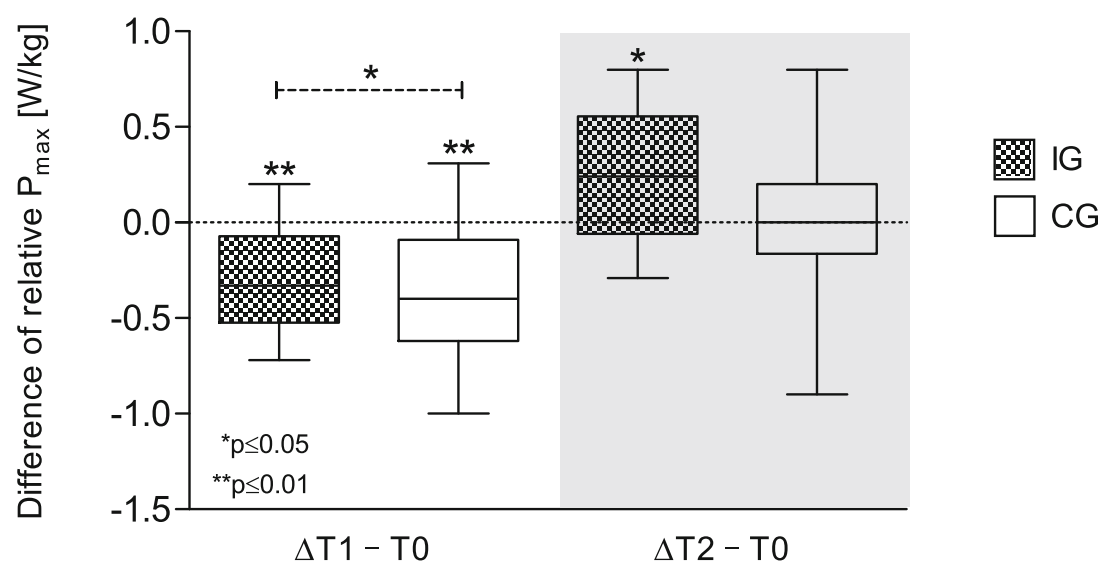


Prism Lab

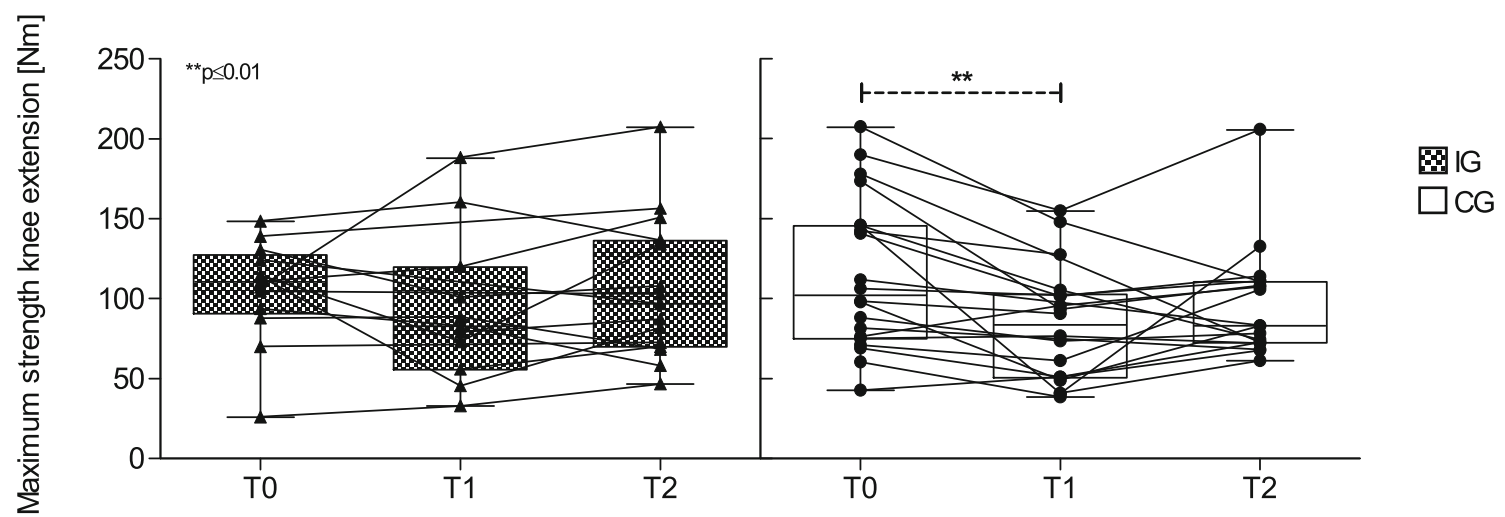

Fig. 4 Maximum strength of knee extensors. Box and whisker plots showing the lower quartile (25th percentile), median (50th percentile), upper quartile ( 75 th percentile), and degree of dispersion as $95 \%$ confidence interval $(95 \% \mathrm{CI})$. Dot plots showing individual values of participants of each group

detected no differences between groups at baseline through our assessments and baseline characteristics, thus we assume that no group was in better physical condition before transplantation. Furthermore, both groups' hospitalization times were the same, which led us to assume that both groups' medical treatment routines were also similar and that they had to handle the same transplant-associated side effects. Although patients were not monitored from hospital discharge till follow-up, the reported amount of physical activity during that time period was similar between groups. This fact had led us to assume that WBV did indeed affect $\mathrm{VO}_{2 \text { peak }}$ and power, quantifiable only after follow-up. As cardiorespiratory fitness is defined by interaction between muscles, the heart, and lungs [23], muscle strength can be regarded as a major criterion of those systems' functioning. Thus almost maintaining the strength of knee extensors and flexors during hospitalization may have facilitated the cardiorespiratory system's ability to recover faster after hospital discharge. Furthermore, WBV might have induced cardiovascular orthostatic stress that reduces the risk of cardiovascular deconditioning caused by bed rest $[49,50]$. There are indications that exercising in upright position can accelerate the rehabilitation process due to increased orthostatic stress, unlike exercising in supine position $[51,52]$ which has mostly been carried out in the CG. Additionally, WBV increases blood flow [53] that may also encourage cardiovascular adaptations.

The aforementioned accelerated physical recovery of the IG compared with the CG is also reflected by enhanced cell metabolism. The IG's body cell mass, which consists of all metabolically active and protein-rich intracellular tissue inter alia muscle mass [54], can be a predictor of malnutrition [55]. It regained baseline values at follow-up, while the CG's dropped. The phase angle also indicates improved metabolism; by measuring cellular membrane integrity and alterations of fluid balance $[56,57]$, the phase angle provides information about the nutritional status of patients and may predict their clinical prognosis [58]. A phase angle improvement could lead to enhanced recovery of the muscular [59] and cardiorespiratory system, and may thus result in a better overall survival [57].
Fig. 5 Difference of jump height over time. Box and whisker plots showing the lower quartile (25th percentile), median (50th percentile), upper quartile (75th percentile), and degree of dispersion as $95 \%$ confidence interval $(95 \% \mathrm{CI})$
Prism Lab

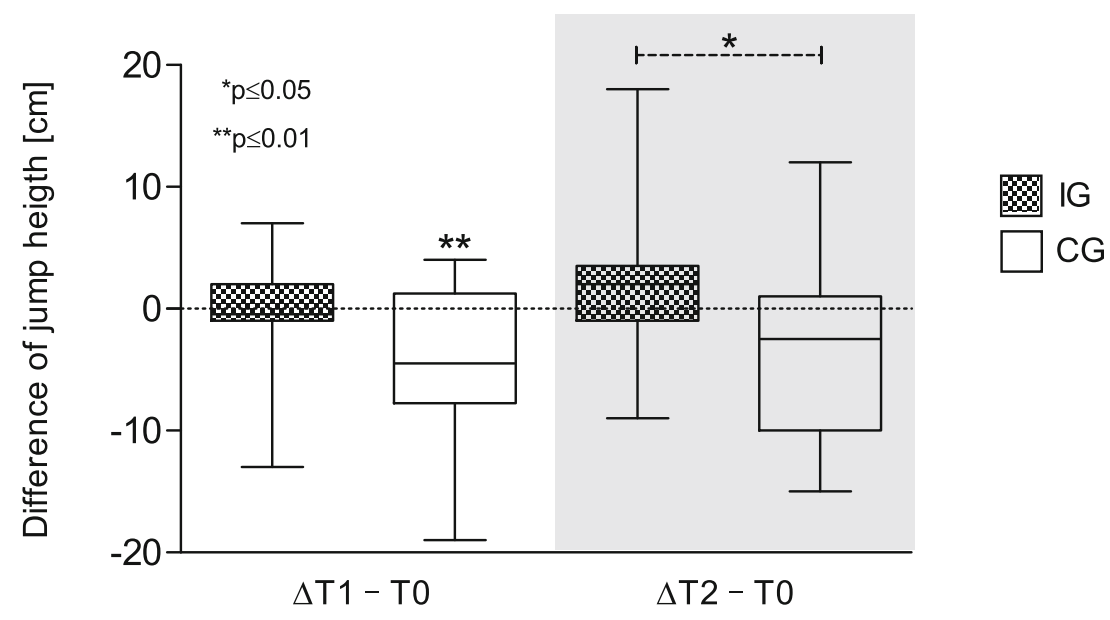




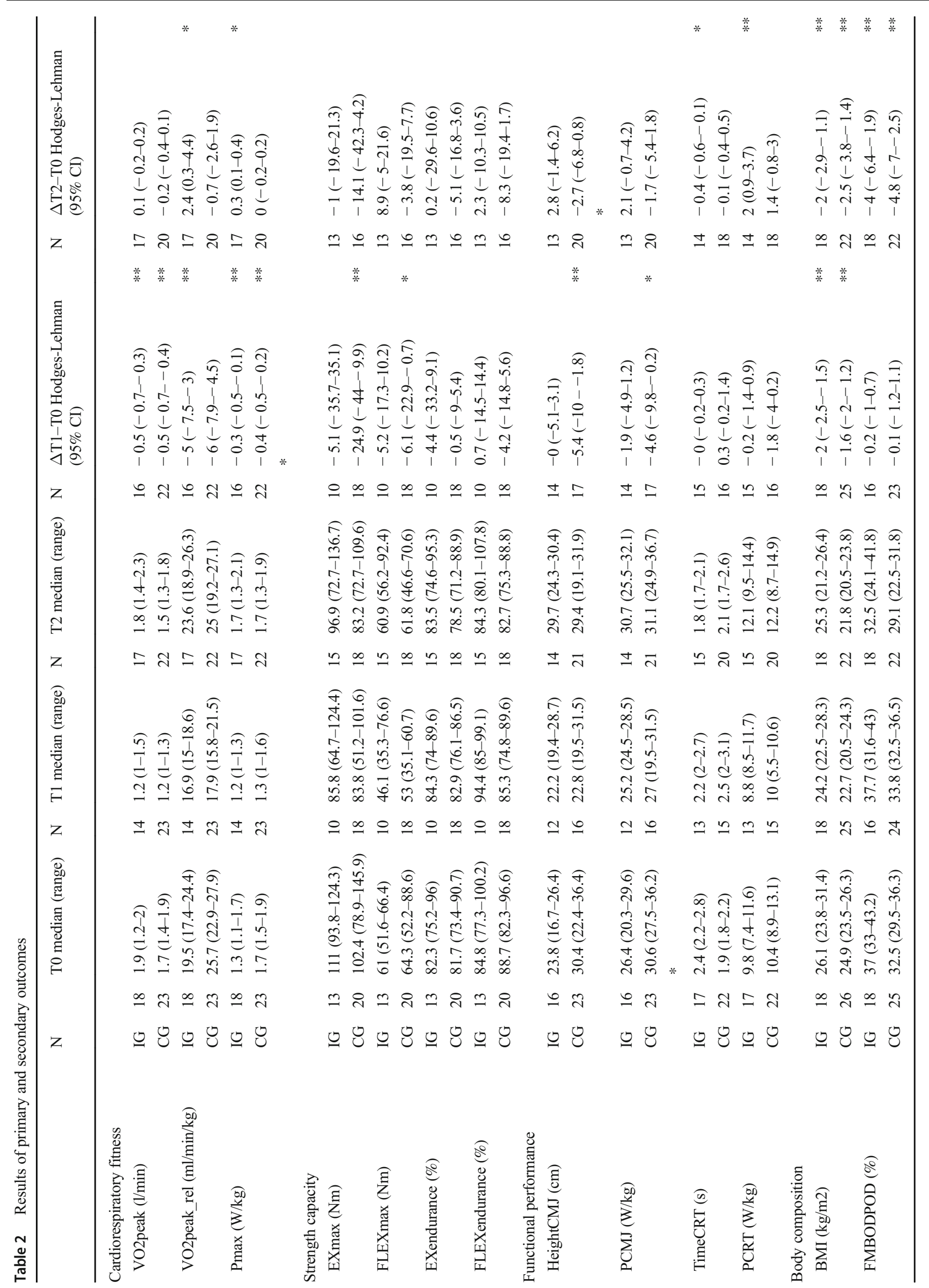




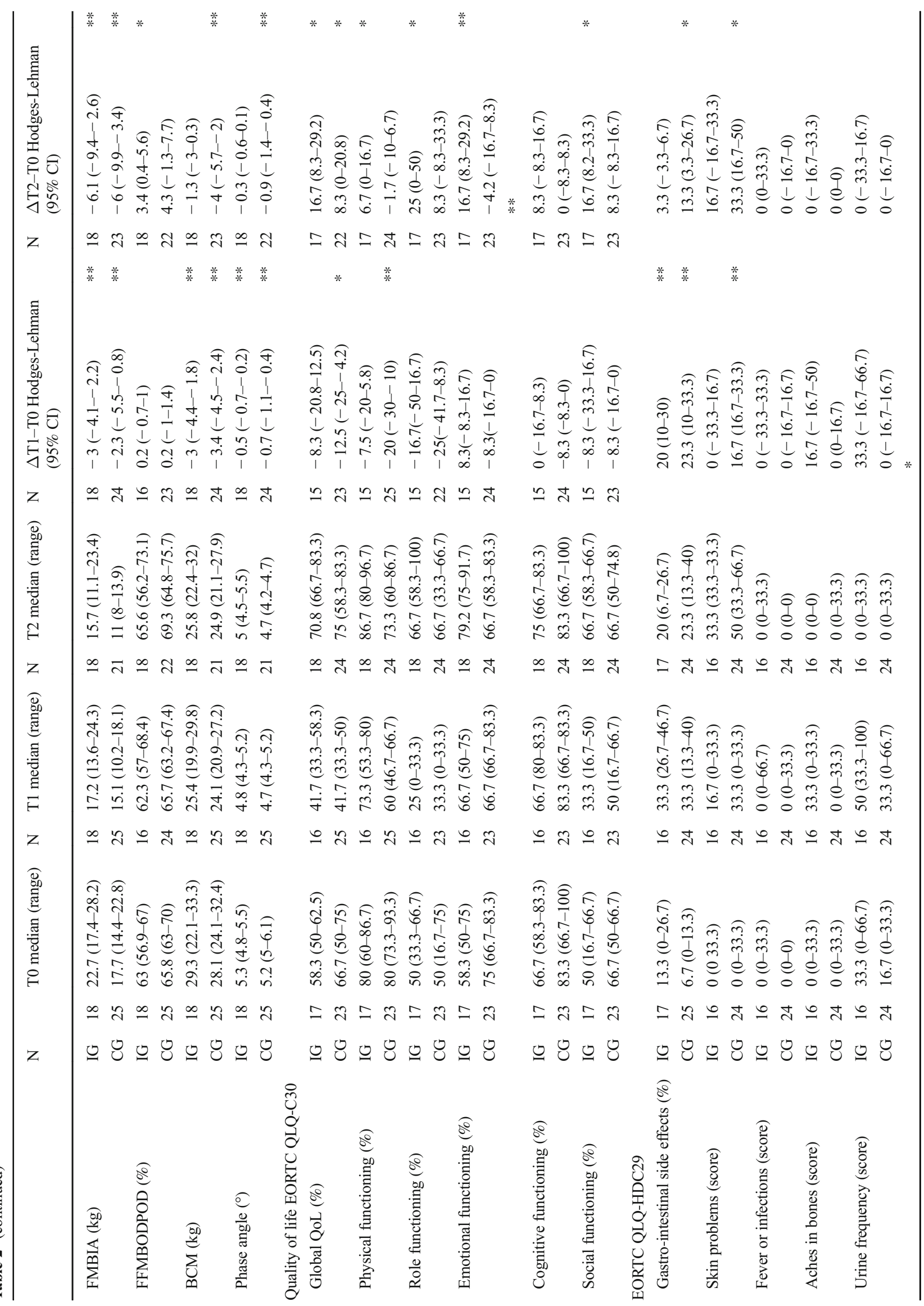




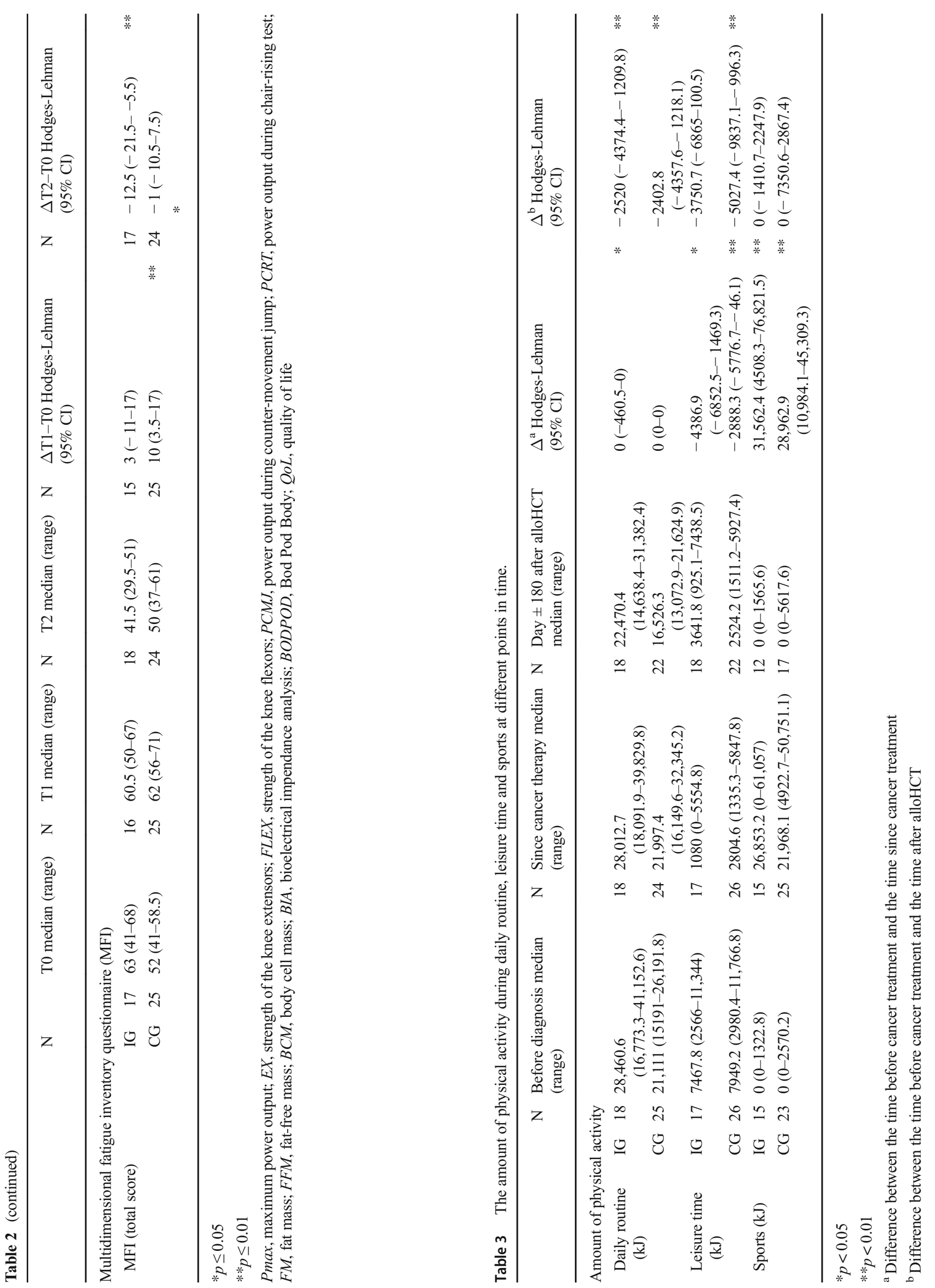


Our findings concerning maximum leg strength and functional performance are in line with other working groups who observed improved strength capacity $[60,61]$ or improved functional performance, i.e., jump height after WBV, especially in weak or untrained persons $[62,63]$. Despite the low amount of IG's maximum leg strength data due to interim technical problems and absolute values which could not be maintained completely, a difference towards the $\mathrm{CG}$ which significantly loses maximum leg strength is shown. Fitts et al. and Widrick et al. [64, 65] observed reduced neuronal activation especially during the first days to weeks of immobilization as a key reason for reduced maximum strength and power afterwards. As WBV enhances the recruitment of motor units [30,31], we assume that WBV can reduce the effects of bed rest on muscle strength by maintaining inter- and intramuscular coordination. Furthermore, WBV influences the stretch-shortening cycle involved significantly in jumping performance $[66,67]$. We thus suspect that WBVinduced neuro-muscular stimulation inhibited the loss of strength of the legs and functional performance during hospitalization [68]. But since the IG's muscle strength and jumping performance did not improve further until follow-up, we assume that WBV's benefits vanished because of discontinued exercising. In contrast, the IG's performance during the chair-rising test improved at followup. We assume that this improvement is more likely due to everyday practice at home - less likely a long-term effect of WBV.

Our results regarding fatigue are comparable to other studies that observed less fatigue due to physical activity during hospitalization in cancer patients [69, 70]. Wiskemann et al. [19] demonstrated that psychological symptoms correlate inversely with physiological performance. Furthermore, and in line with our results, they demonstrated reduced fatigue levels 6 to 8 weeks after hospital discharge. There is evidence that in addition to medical treatment, the fatigue level also depends on physiological factors, such as the hemoglobin level and physical performance [71-73]. Since both groups received the same amount of social contact, we imagine that the IG's aforementioned better physical condition strengthened patients' individual psychological resources and thus led to differences in fatigue; QoL; and reported physical, emotional, social, and role functioning between groups at both hospital discharge and follow-up.

Taking together, WBV seems to affect the cardiorespiratory, neuromuscular, and intracellular systems during alloHCT in different ways: strength of the knee extensors and flexors and jumping performance are directly influenced by enhancing muscular coordination and may be described as acute WBV-triggered adaptations during alloHCT. Cardiorespiratory fitness in turn is indirectly affected and quantifiable only in the long-term, as are the phase angle and body cell mass. We assume that these divergences mainly represent the physiological mechanism of WBV and different abilities of cardiorespiratory, neuromuscular, and intracellular systems to recover after alloHCT. Importantly, WBV seemed to improve psychosocial factors even during hospitalization, persisting for at least 6 months after transplantation.
Our study did not investigate the relative benefit of WBV against conventional resistance training during alloHCT, which is why we are unable to attribute our results to WBV exercises explicitly. We instead aimed to introduce a promising exercise method that may directly and indirectly affect as many physiological and psychosocial aspects as possible relevant for alloHCT patients. Although we have described an effective intervention, we propose comparing different types of exercise with greater sample sizes in future studies to reveal best practice. Furthermore, it might be beneficial to continue intervention exercises long-term after alloHCT to ensure successful overall rehabilitation.

\section{Conclusion}

WBV presents an effective exercise method for patients undergoing alloHCT to preserve maximum strength of leg muscles, functional performance, and QoL, as well as to prevent worsening fatigue during hospitalization. Furthermore, WBV seems to facilitate accelerated physical recovery concerning the cardiorespiratory system, body cell mass, and phase angle. Our IG's superior physical conditioning after follow-up may have entailed better QoL and reduced fatigue level. We conclude that our intervention succeeded by enabling a treatment strategy that improves alloHCT patients' physical and psychological wellbeing. However, to define best practice, we propose to expand the pre- and post-alloHCT intervention period, to investigate the relative benefit of different types of exercises on physiological parameters, and to evaluate their impact on survival.

Acknowledgments We thank all patients for their participation. Furthermore, we thank Jakob Ketterer, Annika Maier, Marie Rodler, Josephine Sachs, Elisa Straub, and Isabelle Walz for assistance during exercise sessions and assessments.

Funding information Open access funding provided by Projekt DEAL. The article processing charge was funded by the German Research Foundation (DFG) and the Albert-Ludwigs-University Freiburg in the funding program Open Access Publishing. The study was funded by the Comprehensive Cancer Center Freiburg and the vibration device was rented by the Leonardis Federation, Germany.

Data availability The dataset generated and analyzed during the current study are available from the corresponding author on reasonable request.

\section{Compliance with ethical standards}

Conflict of interest The authors declare that they have no conflict of interest.

Ethics approval All procedures performed in study involving human participants were in accordance with the ethical standards of the Ethics Committee of the University of Freiburg (reference number 555/15) and with the 1964 Helsinki declaration and its later amendments or comparable ethical standards. 
Informed consent Informed consent was obtained from all individual participants included in the study.

Open Access This article is licensed under a Creative Commons Attribution 4.0 International License, which permits use, sharing, adaptation, distribution and reproduction in any medium or format, as long as you give appropriate credit to the original author(s) and the source, provide a link to the Creative Commons licence, and indicate if changes were made. The images or other third party material in this article are included in the article's Creative Commons licence, unless indicated otherwise in a credit line to the material. If material is not included in the article's Creative Commons licence and your intended use is not permitted by statutory regulation or exceeds the permitted use, you will need to obtain permission directly from the copyright holder. To view a copy of this licence, visit http://creativecommons.org/licenses/by/4.0/.

\section{References}

1. Buehring B, Belavý DL, Michaelis I, Gast U, Felsenberg D, Rittweger J (2011) Changes in lower extremity muscle function after 56 days of bed rest. J Appl Physiol 111:87-94

2. Morishita S, Kaida K, Yamauchi S, Sota K, Ishii S, Ikegame K et al (2013) Relationship between corticosteroid dose and declines in physical function among allogeneic hematopoietic stem cell transplantation patients. Support Care Cancer 21:2161-2169

3. Mosher CE, Redd WH, Rini CM, Burkhalter JE, DuHamel KN (2009) Physical, psychological, and social sequelae following hematopoietic stem cell transplantation: a review of the literature. Psychooncology. 18:113-127

4. Rittweger J, Frost H, Schiessl H, Ohshima H, Alkner B, Tesch P, Felsenberg D (2005) Muscle atrophy and bone loss after 90 days' bed rest and the effects of flywheel resistive exercise and pamidronate: results from the LTBR study. Bone. 36:1019-1029

5. Scott JM, Armenian S, Giralt S, Moslehi J, Wang T, Jones LW (2016) Cardiovascular disease following hematopoietic stem cell transplantation: pathogenesis, detection, and the cardioprotective role of aerobic training. Crit Rev Oncol Hematol 98:222-234

6. Armenian SH, Horak D, Scott JM, Mills G, Siyahian A, Berano Teh $\mathrm{J}$ et al (2017) Cardiovascular function in long-term hematopoietic cell transplantation survivors. Biol Blood Marrow Transplant 23: 700-705

7. Jones LW, Watson D, Herndon JE, Eves ND, Haithcock BE, Loewen $\mathrm{G}$ et al (2010) Peak oxygen consumption and long-term all-cause mortality in nonsmall cell lung cancer. Cancer. 116:4825-4832

8. Myers J, Prakash M, Froelicher V, Do D, Partington S, Atwood JE (2002) Exercise capacity and mortality among men referred for exercise testing. N Engl J Med 346:793-801

9. Wood WA, Deal AM, Reeve BB, Abernethy AP, Basch E, Mitchell SA, Shatten C, Hie Kim Y, Whitley J, Serody JS, Shea T, Battaglini C (2013) Cardiopulmonary fitness in patients undergoing hematopoietic SCT: a pilot study. Bone Marrow Transplant 48:1342-1349

10. Brown JC, Harhay MO, Harhay MN (2015) Physical function as a prognostic biomarker among cancer survivors. Br J Cancer 112: 194-198

11. Cesari M, Kritchevsky SB, Newman AB, Simonsick EM, Harris TB, Penninx BW, Brach JS, Tylavsky FA, Satterfield S, Bauer DC, Rubin SM, Visser M, Pahor M, Health, Aging and Body Composition Study (2009) Added value of physical performance measures in predicting adverse health-related events: results from the Health, Aging and Body Composition Study. J Am Geriatr Soc $57: 251-259$
12. Moreland JD, Richardson JA, Goldsmith CH, Clase CM (2004) Muscle weakness and falls in older adults: a systematic review and meta-analysis. J Am Geriatr Soc 52:1121-1129

13. Rejeski WJ, King AC, Katula JA, Kritchevsky S, Miller ME, Walkup MP et al (2008) Physical activity in prefrail older adults: confidence and satisfaction related to physical function. J Gerontol B Psychol Sci Soc Sci 63:P19-P26

14. Garber CE, Blissmer B, Deschenes MR, Franklin BA, Lamonte MJ, Lee I-M, Nieman DC, Swain DP, American College of Sports Medicine (2011) Quantity and quality of exercise for developing and maintaining cardiorespiratory, musculoskeletal, and neuromotor fitness in apparently healthy adults: guidance for prescribing exercise. Med Sci Sports Exerc 43:1334-1359

15. Baumann FT, Zopf EM, Nykamp E, Kraut L, Schüle K, Elter T, Fauser AA, Bloch W (2011) Physical activity for patients undergoing an allogeneic hematopoietic stem cell transplantation: benefits of a moderate exercise intervention. Eur J Haematol 87:148-156

16. Coleman EA, Coon S, Hall-Barrow J, Richards K, Gaylor D, Stewart B (2003) Feasibility of exercise during treatment for multiple myeloma. Cancer Nurs 26:410-419

17. DeFor TE, Burns LJ, Gold E-MA, Weisdorf DJ (2007) A randomized trial of the effect of a walking regimen on the functional status of 100 adult allogeneic donor hematopoietic cell transplant patients. Biol Blood Marrow Transplant 13:948-955

18. Kim S-D, Kim H-S (2006) A series of bed exercises to improve lymphocyte count in allogeneic bone marrow transplantation patients. Eur J Cancer Care (Engl) 15:453-457

19. Wiskemann J, Dreger P, Schwerdtfeger R, Bondong A, Huber G, Kleindienst N, Ulrich CM, Bohus M (2011) Effects of a partly selfadministered exercise program before, during, and after allogeneic stem cell transplantation. Blood. 117:2604-2613

20. Wiskemann J, Kuehl R, Dreger P, Huber G, Kleindienst N, Ulrich $\mathrm{CM}$ et al (2015) Physical exercise training versus relaxation in allogeneic stem cell transplantation (PETRA study)-rationale and design of a randomized trial to evaluate a yearlong exercise intervention on overall survival and side-effects after allogeneic stem cell transplantation. BMC Cancer 15:619

21. Baumann FT, Kraut L, Schüle K, Bloch W, Fauser AA (2010) A controlled randomized study examining the effects of exercise therapy on patients undergoing haematopoietic stem cell transplantation. Bone Marrow Transplant 45:355-362

22. Jarden M, Baadsgaard MT, Hovgaard DJ, Boesen E, Adamsen L (2009) A randomized trial on the effect of a multimodal intervention on physical capacity, functional performance and quality of life in adult patients undergoing allogeneic SCT. Bone Marrow Transplant 43:725-737

23. Wasserman K (ed) (2005) Principles of exercise testing and interpretation: including pathophysiology and clinical applications, 4th edn. Lippincott Williams \& Wilkins, Philadelphia

24. Cunningham BA, Morris G, Cheney CL, Buergel N, Aker SN, Lenssen P (1986) Effects of resistive exercise on skeletal muscle in marrow transplant recipients receiving total parenteral nutrition. JPEN J Parenter Enteral Nutr 10:558-563

25. Courneya KS, Mackey JR, Jones LW (2000) Coping with cancer: can exercise help? Phys Sportsmed 28:49-73

26. Humpel N, Iverson DC (2005) Review and critique of the quality of exercise recommendations for cancer patients and survivors. Support Care Cancer Off J Multinatl Assoc Support Care Cancer 13:493-502

27. Hazell TJ, Thomas GWR, DeGuire JR, Lemon PWR (2008) Vertical whole-body vibration does not increase cardiovascular stress to static semi-squat exercise. Eur J Appl Physiol 104:903908

28. Marín PJ, Santos-Lozano A, Santin-Medeiros F, Delecluse C, Garatachea N (2011) A comparison of training intensity between whole-body vibration and conventional squat exercise. J 
Electromyogr Kinesiol Off J Int Soc Electrophysiol Kinesiol 21: 616-621

29. Rauch F, Sievanen H, Boonen S, Cardinale M, Degens H, Felsenberg D, Roth J, Schoenau E, Verschueren S, Rittweger J, International Society of Musculoskeletal and Neuronal Interactions (2010) Reporting whole-body vibration intervention studies: recommendations of the International Society of Musculoskeletal and Neuronal Interactions. J Musculoskelet Neuronal Interact 10:193-198

30. Rittweger J (2010) Vibration as an exercise modality: how it may work, and what its potential might be. Eur J Appl Physiol 108:877904

31. Zaidell LN, Mileva KN, Sumners DP, Bowtell JL (2013) Experimental evidence of the tonic vibration reflex during wholebody vibration of the loaded and unloaded leg. PLoS One 8:e85247

32. Miyamoto T, Kamada H, Tamaki A, Moritani T (2016) Lowintensity electrical muscle stimulation induces significant increases in muscle strength and cardiorespiratory fitness. Eur J Sport Sci 16: 1104-1110

33. Gerhardt F, Dumitrescu D, Gärtner C, Beccard R, Viethen T, Kramer T, Baldus S, Hellmich M, Schönau E, Rosenkranz S (2017) Oscillatory whole-body vibration improves exercise capacity and physical performance in pulmonary arterial hypertension: a randomised clinical study. Heart. 103:592-598

34. Liao L-R, Ng GYF, Jones AYM, Pang MYC (2015) Cardiovascular stress induced by whole-body vibration exercise in individuals with chronic stroke. Phys Ther 95:966-977

35. Runge M, Rehfeld G, Resnicek E (2000) Balance training and exercise in geriatric patients. J Musculoskelet Neuronal Interact 1: 61-65

36. Delecluse C, Roelants M, Verschueren S (2003) Strength increase after whole-body vibration compared with resistance training. Med Sci Sports Exerc 35(6):1033-1041 http://journals.lww.com/acsmmsse/Fulltext/2003/06000/Strength_Increase_after_Whole_Body_ Vibration.21.aspx

37. Belavý DL, Miokovic T, Armbrecht G, Rittweger J, Felsenberg D (2009) Resistive vibration exercise reduces lower limb muscle atrophy during 56-day bed-rest. J Musculoskelet Neuronal Interact 9: 225-235

38. Chanou K, Gerodimos V, Karatrantou K, Jamurtas A (2012) Whole-body vibration and rehabilitation of chronic diseases: a review of the literature. J Sports Sci Med 11:187-200

39. Crevenna R, Fialka-Moser S, Rödler M, Keilani C, Zöch M, Nuhr $M$ et al (2003) Safety of whole-body vibration exercise for heart transplant recipients. Phys Med Rehabil Kurortmed 13:286-290

40. Mester J, Kleinöder H, Yue Z (2006) Vibration training: benefits and risks. J Biomech 39:1056-1065

41. Pahl A, Wehrle A, Kneis S, Gollhofer A, Bertz H (2018) Feasibility of whole body vibration during intensive chemotherapy in patients with hematological malignancies-a randomized controlled pilot study. BMC Cancer 18:1-12. https://doi.org/10.1186/s12885-0184813-8

42. Álvarez-Barbosa F, del Pozo-Cruz J, del Pozo-Cruz B, AlfonsoRosa RM, Rogers ME, Zhang Y (2014) Effects of supervised whole body vibration exercise on fall risk factors, functional dependence and health-related quality of life in nursing home residents aged $80+$ . Maturitas. 79:456-463

43. Salhi B, Haenebalcke C, Perez-Bogerd S, Nguyen MD, Ninane V, Malfait TLA et al (2015) Rehabilitation in patients with radically treated respiratory cancer: a randomised controlled trial comparing two training modalities. Lung Cancer Amst Neth 89:167-174

44. Pescatello LS, American College of Sports Medicine, editors. ACSM's guidelines for exercise testing and prescription. 9th ed. Philadelphia: Wolters Kluwer/Lippincott Williams \& Wilkins Health; 2014
45. Scharhag-Rosenberger F, Becker T, Streckmann F, Schmidt K, Berling A, Bernardi A et al (2014) Studien zu körperlichem Training bei onkologischen Patienten: Empfehlungen zu den Erhebungsmethoden. Dtsch Z Für Sportmed 65:304-313

46. Mello M, Tanaka C, Dulley FL (2003) Effects of an exercise program on muscle performance in patients undergoing allogeneic bone marrow transplantation. Bone Marrow Transplant 32:723728

47. Hazell TJ, Lemon PWR (2012) Synchronous whole-body vibration increases $\mathrm{VO}_{2}$ during and following acute exercise. Eur J Appl Physiol 112:413-420

48. Rittweger J, Schiessl H, Felsenberg D (2001) Oxygen uptake during whole-body vibration exercise: comparison with squatting as a slow voluntary movement. Eur J Appl Physiol 86:169-173

49. Levine BD, Zuckerman JH, Pawelczyk JA (1997) Cardiac atrophy after bed-rest deconditioning: a nonneural mechanism for orthostatic intolerance. Circulation. 96:517-525

50. Perhonen MA, Zuckerman JH, Levine BD (2001) Deterioration of left ventricular chamber performance after bed rest: "cardiovascular deconditioning" or hypovolemia? Circulation. 103:1851-1857

51. Convertino VA (1983) Effect of orthostatic stress on exercise performance after bed rest: relation to inhospital rehabilitation. J Cardpulm Rehabil 53(7):660-663

52. Savard GK, Stonehouse MA (1995) Cardiovascular response to orthostatic stress: effects of exercise training modality. Can J Appl Physiol Rev Can Physiol Appl 20:240-254

53. Lythgo N, Eser P, De Groot P, Galea M (2009) Whole-body vibration dosage alters leg blood flow. Clin Physiol Funct Imaging 29: 53-59

54. Moore FD, Boyden CM (1963) Body cell mass and limits of hydration of the fat-free body: their relation to estimated skeletal weight. Ann N Y Acad Sci 110:62-71

55. Pirlich M, Schütz T, Ockenga J, Biering H, Gerl H, Schmidt B et al (2003) Improved assessment of body cell mass by segmental bioimpedance analysis in malnourished subjects and acromegaly. Clin Nutr Edinb Scotl 22:167-174

56. Barbosa-Silva MCG, Barros AJD, Wang J, Heymsfield SB, Pierson RN (2005) Bioelectrical impedance analysis: population reference values for phase angle by age and sex. Am J Clin Nutr 82:49-52

57. Bosy-Westphal A, Danielzik S, Dörhöfer R-P, Later W, Wiese S, Müller MJ (2006) Phase angle from bioelectrical impedance analysis: population reference values by age, sex, and body mass index. JPEN J Parenter Enteral Nutr 30:309-316

58. Urbain P, Birlinger J, Ihorst G, Biesalski H-K, Finke J, Bertz H (2013) Body mass index and bioelectrical impedance phase angle as potentially modifiable nutritional markers are independent risk factors for outcome in allogeneic hematopoietic cell transplantation. Ann Hematol 92:111-119

59. Yamada M, Kimura Y, Ishiyama D, Nishio N, Otobe Y, Tanaka T et al (2019) Phase angle is a useful indicator for muscle function in older adults. J Nutr Health Aging 23:251-255

60. Lachance C, Weir P, Kenno K, Horton S (2012) Is whole-body vibration beneficial for seniors? Eur Rev Aging Phys Act 9:51-62

61. Zhang L, Weng C, Liu M, Wang Q, Liu L, He Y (2014) Effect of whole-body vibration exercise on mobility, balance ability and general health status in frail elderly patients: a pilot randomized controlled trial. Clin Rehabil 28:59-68

62. Colson SS, Petit P-D (2013) Lower limbs power and stiffness after whole-body vibration. Int J Sports Med 34:318-323

63. Cochrane DJ, Stannard SR (2005) Acute whole body vibration training increases vertical jump and flexibility performance in elite female field hockey players. Br J Sports Med 39:860-865

64. Fitts RH, Riley DR, Widrick JJ (2001) Functional and structural adaptations of skeletal muscle to microgravity. J Exp Biol 204(Pt 18):3201-3208 
65. Widrick JJ, Knuth ST, Norenberg KM, Romatowski JG, Bain JL, Riley DA et al (1999) Effect of a 17 day spaceflight on contractile properties of human soleus muscle fibres. J Physiol 516(Pt 3):915930

66. Kopper B, Csende Z, Trzaskoma L, Tihanyi J (2014) Stretchshortening cycle characteristics during vertical jumps carried out with small and large range of motion. J Electromyogr Kinesiol Off J Int Soc Electrophysiol Kinesiol 24:233-239

67. Gollhofer A, Strojnik V, Rapp W, Schweizer L (1992) Behaviour of triceps surae muscle-tendon complex in different jump conditions. Eur J Appl Physiol 64:283-291

68. Lamont HS, Cramer JT, Bemben DA, Shehab RL, Anderson MA, Bemben MG (2008) Effects of 6 weeks of periodized squat training with or without whole-body vibration on short-term adaptations in jump performance within recreationally resistance trained men. $\mathrm{J}$ Strength Cond Res 22:1882-1893

69. Chang P-H, Lai Y-H, Shun S-C, Lin L-Y, Chen M-L, Yang Y, Tsai JC, Huang GS, Cheng SY (2008) Effects of a walking intervention on fatigue-related experiences of hospitalized acute myelogenous leukemia patients undergoing chemotherapy: a randomized controlled trial. J Pain Symptom Manag 35:524-534

70. Dimeo FC, Stieglitz RD, Novelli-Fischer U, Fetscher S, Keul J (1999) Effects of physical activity on the fatigue and psychologic status of cancer patients during chemotherapy. Cancer. 85:2273-2277

71. Bower JE (2014) Cancer-related fatigue - mechanisms, risk factors, and treatments. Nat Rev Clin Oncol 11:597-609

72. Paddison JS, Temel JS, Fricchione GL, Pirl WF (2009) Using the differential from complete blood counts as a biomarker of fatigue in advanced non-small-cell lung cancer: an exploratory analysis. Palliat Support Care 7:213

73. Wagner LI, Cella D (2004) Fatigue and cancer: causes, prevalence and treatment approaches. Br J Cancer 91:822-828

Publisher's note Springer Nature remains neutral with regard to jurisdictional claims in published maps and institutional affiliations. 